\title{
SERIA A BANALIDADE DO MAL UM CAMINHO PARA A COMPREENSÃO DA VIOLÊNCIA ESCOLAR?
}

\author{
Pâmela Esteves ${ }^{1}$
}

\section{Resumo:}

Esse artigo tem o objetivo de investigar as práticas de violência que desafiam o cotidiano escolar. Trata-se de buscar compreender as estruturas que possibilitam a construção e a sustentação dessas práticas. É com esse desejo de compreensão que nos colocamos na companhia de Hannah Arendt e Immanuel Kant, com o propósito de identificarmos o mal como uma fonte estrutural na formação das práticas violentas que se configuram nas relações escolares. Para melhor compreensão dos argumentos, o artigo percorre um caminho de apresentação das contribuiçõos de Arendt e Kant sobre a maldade humana, e problematiza, a partir das narrativas discentes, se na motivação para o agir com violência pode ser fundamentada na banalização da maldade. Do ponto de vista metodológico, os argumentos defendidos neste texto são oriundos de uma pesquisa no campo educacional sobre as práticas de bullying que desafiam as relações intersubjetivas no cotidiano escolar. A pesquisa foi desenvolvida entre os anos de 2014 - 2017. O campo investigativo contemplou uma escola pública de grande porte da rede estadual da cidade do Rio de Janeiro. Os sujeitos da pesquisa foram estudantes do Ensino Médio. A pesquisa foi realizada em três etapas metodológicas: 1- levantamento bibliográfico; 2- Observação do cotidiano escolar e aplicação de questionários aos estudantes. 3- A partir dos dados coletados nos questionários foi elaborado um roteiro de entrevistas semiestrurado e aplicado aos sujeitos da pesquisa. Esse texto foi escrito contemplando todas as etapas da pesquisa e aponta como conclusão que a banalização da maldade é uma expressão da violência escolar nas sociedades contemporâneas massificadas.

Palavras-chaves: Violência escolar; banalidade do mal; Hannah Arendt; cotidiano escolar.

\section{WOULD THE BANALITY OF EVIL BE A WAY TO UNDERSTAND SCHOOL VIOLENCE?}

\begin{abstract}
:
This article aims to investigate the practices of violence that challenge the school routine. It is about seeking to understand the structures that make it possible to build and sustain these practices. It is with this desire for understanding that we place ourselves in the company of Hannah Arendt and Immanuel Kant, with the purpose of identifying evil as a structural source in the formation of violent practices that are configured in school relations. For a better understanding of the arguments, the article follows a path of presentation of Arendt and Kant's contributions on human evil, and questions, from the student narratives, whether the motivation to act with violence can be based on the trivialization of evil. From the methodological point of view, the arguments defended in this text come from a research in the educational field on the practices of bullying that challenge the intersubjective relationships in the school routine. The research was carried out between the years $2014-2017$. The investigative field included a large public school in the state network of the city of Rio de Janeiro. The research subjects were high school students. The research was carried out in three methodological steps: 1- bibliographic survey; 2 Observation of school routine and application of questionnaires to students. 3- Based on the data collected in the questionnaires, a semi-structured interview script was developed and applied to the research subjects. This text was written covering all stages of the research and points out as a conclusion that the trivialization of evil is an expression of school violence in mass contemporary societies.
\end{abstract}

Keywords: School violence; banality of evil; Hannah Arendt; everyday school.

1 Doutora em Educação pela PUC-RIO. Professora adjunta do Departamento de Educação da Universidade do Estado do Rio de Janeiro - UERJ. Professora do Programa de Pós-Graduação em Educação, Comunicação e Culturas na Periferia, da Universidade do Estado do Rio de Janeiro - PPGECC - UERJ/FEBF. E-mail: pamelasme84@gmail.com. 


\section{Iniciando uma problematização}

A violência desafia o cotidiano escolar. Tal desafio envolve não apenas o desempenho dos discentes, comumente utilizado como critério de mensuração da eficácia escolar. A violência tem um potencial destruidor que vai além dos aspectos materialistas da vida, e na escola, afeta as relações intersubjetivas dos estudantes, marca seus processos identitários e viola suas escolhas. Nesse artigo o objetivo não é tematizar sobre as práticas de violência escolar, mas sim buscar compreender as estruturas que possibilitam a construção e a sustentação dessas práticas. É com esse desejo de compreensão que nos colocamos na companhia de Hannah Arendt e Immanuel Kant, com o propósito de identificarmos o mal como uma fonte estrutural na formação das práticas violentas que se configuram nas relações escolares.

A questão do mal atravessa toda a reflexão político-filosófica arendtiana sobre a experiência totalitária. Diante da dificuldade em entender a existência dos campos de concentração nazistas, Hannah Arendt iniciou um longo exercício de compreender o que havia acontecido durante a Segunda Guerra Mundial. O resultado desse exercício foi, num primeiro momento, a publicação de As origens do totalitarismo, onde Arendt $(1989$, p. 64) afirma "um abismo se abriu diante de mim".

Após sua chegada aos Estados Unidos, em 1941, Hannah Arendt se dedicou às questões relacionadas à situação dos judeus na Europa, colaborando com várias revistas ligadas aos imigrantes europeus e participando intensamente dos debates travados por intelectuais que haviam sido obrigados a fugir de seus países de origem. "A descoberta das atrocidades nazistas nos campos de extermínio conduziu-a, no entanto, aos problemas que estariam no centro de seu pensamento nos próximos anos" (BIGNOTO, 2012, p. 19).

Ao constatar o mal que havia sido empregado nos campos de concentração, Arendt (1999) apontou para a brutalidade da violência perpetrada pelos governos totalitários e mostrou a insuficiência das teorias e categorias científicas, econômicas e políticas tradicionais para captar e explicar a novidade do que estava acontecendo. As origens do totalitarismo funcionou como uma resposta, uma tentativa de compreensão da novidade que se anunciava, uma forma de reconciliação com o mundo diante do estranhamento que a experiência totalitária havia causada nela como judia perseguida pelo nazismo e como intelectual desafiada a pensar seu tempo. "Arendt buscou narrar o totalitarismo para superar o trauma de conhecer Auschwitz" (JARDIM, 2011, 23).

\begin{tabular}{|c|c|c|c|c|}
\hline Qenista Dialectus & Ano 9 & n. 19 & Agosto - Dezembro 2020 & p. $176-196$ \\
\hline
\end{tabular}


Em As origens do totalitarismo o mal realizado pelos regimes totalitários foi caracterizado por Arendt (1999) como um domínio total mais opressor que a escravidão e a tirania; e mais destruidor que a miséria econômica e o expansionismo territorial. Tratava-se de um mal radical, no sentido que Kant havia dado ao termo, ou seja, um mal extremo, que possui fundamentos ideológicos e que se caracteriza pela monstruosidade de suas ações.

Ao alcançar todas as esferas da vida, o controle total pretendia atingir todas as formas de expressividade humana adotando como critério de legitimidade governamental a redução dos humanos a seres naturais. O recurso à categoria do mal é uma forma de tentar compreender o inexplicável e visa aproximar-se reflexivamente da primeira tentativa de constituição de uma forma de governo, no Ocidente, baseada na purificação e no extermínio dos seres humanos. Trata-se, assim, de pensar o mal nas sociedades secularizadas sem recorrer a nenhum tipo de explicação religiosa.

O tema do mal, em Arendt (1999), não tem como pano de fundo a malignidade, a perversão ou o pecado humano. A novidade da sua reflexão reside justamente em evidenciar que os seres humanos podem realizar ações inimagináveis, do ponto de vista da destruição e da morte, sem qualquer tipo de motivação substantiva ou ontológica. O pano de fundo da argumentação proposta pela autora é o processo de naturalização da sociedade e de artificialização da natureza, ocorrido com a massificação, a industrialização e a tecnificação das decisões e das organizações humanas na contemporaneidade. O mal é abordado, desse modo, em uma perspectiva ético-política.

Dessa forma, o mal investigado por Arendt (1999) não é oriundo de nenhum tipo de sentimento de vingança, ódio, retaliação ou represália. Por isso, nesse artigo buscamos entender se há uma relação entre esse tipo de "mal sem raízes", descrito por Arendt (1999), e as práticas violentas que marcam as relações entre pares na escola. Para melhor compreensão dos argumentos, o artigo percorre um caminho de apresentação das contribuições de Arendt e Kant sobre a maldade humana, e problematiza, a partir das narrativas discentes, se na motivação para o agir com violência pode ser fundamentada na banalização da maldade.

Do ponto de vista metodológico, os argumentos defendidos neste texto são oriundos de uma pesquisa no campo educacional sobre as práticas de bullying que desafiam as relações intersubjetivas no cotidiano escolar. A pesquisa foi desenvolvida entre os anos de 2014 - 2017. O campo investigativo contemplou uma escola pública de grande porte da rede estadual da cidade do Rio de Janeiro. Os sujeitos da pesquisa foram estudantes do Ensino Médio. A pesquisa foi realizada em três etapas metodológicas: 1- levantamento bibliográfico; 2-

\begin{tabular}{|l|l|l|l|l|}
\hline Qevista Qialectus & Ano 9 & n. 19 & Agosto-Dezembro 2020 & p. $176-196$ \\
\hline
\end{tabular}


Observação do cotidiano escolar e aplicação de questionários aos estudantes. 3- A partir dos dados coletados nos questionários foi elaborado um roteiro de entrevistas semiestrurado e aplicado aos sujeitos da pesquisa. Esse texto foi escrito contemplando todas as etapas da pesquisa.

\section{O mal não é banal, e sim banalizado}

Em As origens do totalitarismo, Arendt (1989) argumentou sobre o tema do mal no âmbito da reflexão kantiana sobre o mal radical. Kant (1974) percebeu que o mal pode ter origem não nos instintos ou na natureza pecaminosa do homem e, sim, nas faculdades racionais que o fazem livre. Dessa forma, o mal não possui dimensão ontológica, mas contingencial. Ele acontece a partir da interação e da reação das faculdades espirituais humanas às suas circunstâncias. O mal no pensamento kantiano é radical, pois se trata de uma espécie de rejeição consciente ao bem e está atrelado, ainda, ao uso dos seres humanos como meios, instrumentos, e não do reconhecimento do ser humano como fim em si mesmo.

Em sua investigação, Arendt (1999) conserva parte das afirmações kantianas assumindo que o mal está presente na racionalidade e na liberdade humana, mas a filósofa acrescenta à reflexão kantiana uma dimensão histórico-política, considerando as especificidades vividas no século XX. Em 1793, na primeira parte da obra A religião dentro dos limites da simples razão, Kant começou a estudar o mal e o classificou como radical. A radicalidade do mal estaria na atitude humana de transformar seus desejos em normas para construções de novas leis morais. Kant (1974) reconhece que a razão é a instância suprema do ser humano, mas ela é finita, e é justamente essa condição de finitude da razão que possibilita ao ser humano praticar o mal, transformando seus desejos e paixões em "imperativos categóricos".

Nesse sentido, a teoria kantiana sobre o mal radical postula que o humano é propenso ao mal porque é livre, e essa liberdade é viabilizada pela vontade. Para facilitar o entendimento, Kant (1974) recorre à metáfora luterana do homem curvo, que tem a capacidade de se curvar sobre si mesmo, dado seu egoísmo. O mal se apresenta como a curvatura, ele é radical, mas não é definitivo, ou seja, não é absoluto, pois os seres humanos podem se aprumar basta que a fissura entre a lei do dever moral e a lei dos prazeres e satisfações sensíveis seja superada.

\begin{tabular}{|l|l|l|l|l|}
\hline Qenista Dialectus & Ano 9 & n. 19 & Agosto - Dezembro 2020 & p. $176-196$ \\
\hline
\end{tabular}


Dessa forma, podemos compreender que o mal radical está no livre arbítrio, isto é, que o ser humano é livre para obedecer ou desobedecer (SOUKI, 2006). Em Kant (1974), a lei moral é inerente à natureza da razão, mas não à natureza humana, pois devido à finitude e à liberdade da natureza humana, os seres humanos não necessariamente seguirão à lei moral. $\mathrm{O}$ mal, dentro do pensamento kantiano, nos parece ser um desvio moral que converte nossas sensibilidades expressadas em desejos e paixões em normas morais e transformam essas novas normas em prazeres absolutos. O resultado é a instauração do egoísmo com seus desejos inferiores e superiores (SOUKI, 2006, p. 19).

Em suma, a possibilidade do mal radical encontra-se no fato do humano ser livre. É dentro do contexto de liberdade que ocorre o conflito entre o bem (liberdade moral) e o mal (desvio; abandono da liberdade). Para Kant (1974), o ser humano possui uma propensão inata para a maldade, ou seja, a maldade não pode ser extirpada da condição humana, pois isso acarretaria o fim da liberdade. Nesse sentido, o mal radical é universal, mas tem seus limites, pois, na doutrina kantiana, há nos seres humanos uma disposição originária para o bem. Neste sentido, o mal nunca poderia ser absoluto. $\mathrm{O}$ mal radical tem seus limites na incapacidade de destruir a lei moral e na disposição originária e plenamente humana para o bem. "Aceitar a malignidade absoluta do homem seria pôr em risco a validade da lei moral e consequentemente toda argumentação kantiana" (FELÍCIO, 2005, p. 04).

No pensamento kantiano (1974), a propensão do ser humano para fazer o mal ocorre em três níveis:

1- O nível inferior: a fragilidade da natureza humana diante da tentação;

2- O nível mediano: a impureza do coração em misturar os valores morais e imorais;

3- O nível superior: a maldade, a corrupção do coração humano. Quando o livre arbítrio adota como máxima a subordinação da lei moral por desejos e paixões.

Essa subordinação pode ser chamada de perversidade.

A vontade é má quando a satisfação de seu desejo de felicidade é condição do seguimento da lei moral. É nessa inversão dos dois móveis de determinação da vontade que reside o mal radical. (...) Para Kant, a vontade má que se recusasse à lei moral seria absurda (SOUKI, 2006 p. 22).

Mas, apesar de reconhecer que o mal é inerente à condição humana, Kant (1974) adverte que a possibilidade de superação do mal é uma tarefa de responsabilidade de todos os seres humanos. A superação do mal estaria numa espécie de conversão, um apelo feito pelos

\begin{tabular}{|l|l|l|l|l|}
\hline Qenista Dialectus & Ano 9 & n. 19 & Agosto-Dezembro 2020 & p. $176-196$ \\
\hline
\end{tabular}


próprios seres humanos ao restabelecimento original da propensão que os seres humanos têm para praticar o bem. Se o último nível da maldade humana é a perversão, Kant (1974) afirma a possibilidade da conversão, pois o mal não é absoluto para destruir o bem, ele apenas consegue subjugá-lo.

O conceito de mal radical foi o ponto de partida de Arendt (1989) quando ela relacionou a radicalidade do mal à novidade e ao assombro diante das informações chegadas às suas mãos nos Estados Unidos, em 1943, sobre Auschwitz. Arendt (1989) associou o mal radical aos campos de concentração, base de sustentação daquela nova forma de governo. " $\mathrm{O}$ mal radical está associado ao totalitarismo, organização governamental e sistemática da vida dos homens, prescindindo do discurso e da ação, considerando-os meros animais, controláveis e descartáveis" (SOUKI, 2006, p. 63). É uma forma de governar sustentada, explicitamente, no pressuposto do extermínio de setores da população e não apenas na sua opressão ou instrumentalização. Isso não diz respeito apenas à exclusão sociopolítica do criminoso, nem à eliminação do opositor ou inimigo, mas a atualização da lógica da descartabilidade humana inerente àquelas formas de governo.

\footnotetext{
Ao considerar a população apenas do ponto de vista biológico, laborante, o governo total tratou de eliminar qualquer instituição ou vínculo humano que pudesse dar abrigo à solidariedade, à ação e à diferenciação entre os indivíduos. Destruindo o mundo comum (partidos, família, arte, religiões, sindicatos, justiça e outras formas de organização), no qual as pessoas poderiam ser amparadas e respeitadas, os governos totalitários constituíram-se baseados na propaganda, na espetacularização, na atomização, na solidão, na padronização, na coletivização das massas e na redução do homem a animal, ocupado exclusivamente com a sua reprodução biológica. Os regimes totais conceberam os homens apenas como seres vivos e prolongaram esse critério na escolha dos merecedores da vida (AGUIAR, 2010, p. 14).
}

Contudo, o que Arendt (1989) considera como um mal radical é um desdobramento da teoria do mal investigada por Kant (1974). Para Arendt (1989), o mal radical que aparece nos regimes totalitários transcende parte das conceituações kantianas, pois a experiência totalitária trouxe uma nova espécie de agir humano, na qual não houve limites à capacidade de deformação da natureza humana. "Um sistema onde todos se tornaram supérfluos" (Arendt, 1989, p. 89). Arendt (1989) aprofunda a análise kantiana, quando afirma que o mal pode sim ser absoluto e maligno. Essa visão é histórica e faz referência a uma dimensão política do mal, na qual um Estado Nacional foi capaz de produzir agentes heterônomos reprodutores de seus objetivos. 
Souki (2006) defende que o fato de Arendt (1989) investigar o mal de um ponto de vista político desconstrói a ideia da insuficiência do conceito kantiano de mal radical, como referencial teórico de investigação do totalitarismo. Segundo Souki (2006), não há incompatibilidade entre o conceito de mal radical kantiano e a expressão banalidade do mal arendtiana, pois o conceito de mal radical pode abarcar todas as modalidades do mal que apareceram nos regimes totalitários, desde que se parta do princípio de que para Kant (1974, p. 197) "o mal pode sim destruir a legalidade na sua contingência, mas não a moralidade na sua incondicionalidade". Se o mal fosse capaz de destruir incondicionalmente a moralidade, seria impossível a vida humana em sociedade.

A confusão entre o mal radical e a banalidade do mal ocorreu, segundo Souki (2006) e Bernstein (2008), porque Arendt (1999) teria confundido radical com absoluto. Em 1945, Arendt (1989) afirmou que a questão do mal seria uma grande problemática para os intelectuais do pós-guerra, mas parece que ela se equivocou, pois a maioria dos intelectuais evitou discutir o mal. Em carta direcionada ao filósofo Scholem, Arendt (1978) chegou a afirmar que teria mudado de opinião em relação ao mal.

\footnotetext{
Agora estou convencida de que o mal nunca pode ser radical, se não unicamente extremo, e que não possui profundidade e nem tampouco dimensão demoníaca. Pode se estender pelo mundo inteiro, pois é como um fungo que invade as superfícies e desafia o pensamento, pois quando este vai atrás das raízes do mal não encontra nada. Por isso só o bem tem profundidade.
}

Quando Arendt (1999) escreve para Scholem recusando o conceito de mal radical, ela o faz porque associou radical a algo profundo, absoluto e essencializado. Para Arendt (1999), o contato com o caso Eichmann revelou que o mal não possui profundidade e nunca pode ser demoníaco. O mal pode se tornar banalizado por determinadas contingências históricas e políticas, já o mal radical surge quando o ser humano deixa de ser um fím em si mesmo, torna-se supérfluo diante de outros humanos, ou seja, perde sua dignidade (Kant, 1974) e seu reconhecimento (Taylor, 2001). A partir desse ponto de vista, a banalidade do mal pode ser considerada uma evolução do mal radical (presente nos regimes totalitários), uma roupagem contemporânea à radicalidade do mal. "O mal banalizado não seria uma novidade enquanto essência, mas sim uma novidade enquanto fenômeno (aparência)" (SOUKI, 2006, p. 97).

Hannah Arendt pressupõe que o mal, embora não sendo radical, possa ser, contudo, extremo. Se, para ela, radical e extremo estão em relação de exclusão, para Kant o conceito de mal radical não exclui as formas extremas de mal. Quando Kant admite a

\begin{tabular}{|l|l|l|l|l|}
\hline Revista & Ano 9 & n. 19 & Agosto-Dezembro 2020 & p. $176-196$ \\
\hline
\end{tabular}


possibilidade de uma dinâmica de expansão do mal radical, ele está, exatamente, levando isso em conta. Embora ele não se refira a isso de forma explícita, a ideia de um mal extremo aparece quando ele se refere a um "estado ética natural", descrito como "um combate público mútuo contra os princípios da virtude e um estado de carência interna de moralidade". O "estado ético natural" não significa ausência de lei, mas arbitrariedade, na qual cada um se dá a sua própria lei. Pode-se pensar também na possibilidade dessa arbitrariedade ir além do plano individual, atingir grupos e culminar no Estado, quando ele se encontra revestido de características totalitárias. Esse é um ponto bastante significativo, pois se refere ao mal radical exatamente na sua dimensão política. Mais uma vez o pensamento de Hannah Arendt parece convergir para o de mal radical kantiano, sem que, contudo, ela tenha se dado conta disso (SOUKI, 2006, p. 98).

Dessa forma, acreditamos, assim como Souki (2006), que o mal radical kantiano foi o ponto de partida de Arendt (1989) para o compreender a maldade empregada na experiência totalitária. E foi a partir dos estudos sobre o totalitarismo, destacando as análises sobre a crise política de autoridade que viabilizou a instauração dos regimes totalitários, que Arendt (1999) conseguiu olhar para a personalidade de Eichmann e enxergar a falta de profundidade e a ausência de enraizamento das razões e intenções do oficial nazista. Se, no mal radical, o ponto central é a superficialidade da natureza humana, na banalidade do mal o foco está na irreflexão dos seres humanos. Logo, há uma complementaridade entre os dois conceitos, pois ao transformar alguns humanos em seres superficiais e outros em seres supérfluos e descartáveis, os regimes totalitários contribuíram para que esses sujeitos perdessem a capacidade de refletir sobre suas próprias atitudes.

Segundo Arendt (1999), a banalidade do mal esconde seu verdadeiro lado, o escândalo do mal. Foi esse escândalo que a levou a aceitar o convite da revista The New Yorker para fazer a cobertura do julgamento de Eichmann ocorrido em Jerusalém, em 1962. Eichmann foi o principal responsável pelo envio dos judeus aos campos de concentração. Em todos os relatos de Arendt (1999), verificamos uma profunda perplexidade com a forma de Eichmann falar das suas atividades militares no III Reich. Ele usava clichês, palavras de ordens e a lógica da obrigação do bom funcionário para justificar o seu comportamento. Para Eichmann, em nenhum momento, ele poderia ser enquadrado como criminoso, pois apenas cumpria a sua obrigação. Assim, em sua maneira de argumentar, o seu crime seria sua lealdade às leis. Arendt (1999), de certa forma, reconhece que aquele oficial nazista era um ser humano normal, um bom pai de família, não possuía um ódio explícito ao povo judeu e não era motivado por uma vontade de transgredir ou por qualquer outro tipo de maldade.

Ao se debruçar sobre o caso Eichmann, Arendt (1999) descobre uma nova explicação para os atos maus, isto é, um mal sem relação com a maldade e que por isso podia ser banalizado, podia ocupar o lugar da normalidade. E isto era o que lhe causava mais espanto.

\begin{tabular}{|l|l|l|l|l|}
\hline Qevista Oialectus & Ano 9 & n. 19 & Agosto-Dezembro 2020 & p. $176-196$ \\
\hline
\end{tabular}


Trata-se do mal sem causa aparente, sem raízes, sem profundidade, sem fundamento. $\mathrm{O}$ praticante desse mal não reflete sobre as consequências de suas ações, ele age semelhante a uma engrenagem da maquinaria burocrática, não há profundidade em seus argumentos, suas práticas apontam para ações racionais, mas sem justificativas socialmente coerentes. O mal "é como um fungo, não tem raiz, nem semente" (KOHN, 2001, p. 14), mas se espalha rapidamente na superficialidade daqueles que não pensam.

\section{A banalização do mal no cotidiano escolar}

De acordo com as narrativas estudantis obtidas por meio de entrevistas no contexto da pesquisa citada na introdução desse texto, o mal presente nas práticas de bullying é banalizado por que não tem explicação convincente, não tem motivação relevante, não é ideológico, não é patológico e muito menos demoníaco, tal como aprendemos com Arendt (1999, p. 124). Contudo, o fato do mal presente nas práticas de bullying ser banalizado, não significa que seja comum, natural, sem importância ou gravidade. "Um ato mal torna-se banal não por ser comum, mas por ser vivenciado como se fosse algo comum. A banalidade não é normalidade, mas passa-se por ela, ocupa indevidamente o lugar da normalidade" (ANDRADE, 2010, p. 19).

O bullying não é um comportamento comum, mas assume o lugar de comum, e, em geral, é tratado pelas escolas e pelas famílias como algo menor, corriqueiro, uma simples brincadeira de criança. Essa visão só contribui para fortalecer o processo de banalização do mal presente no bullying. O bullying não é comum, não é natural, mas sim um comportamento maliciosamente banal, mas não no sentido de trivial. "O mal por si nunca é trivial, embora ele possa se manifestar de tal maneira que ocupe o lugar daquilo que é comum" (ASSIS, 2001, p. 144).

É exatamente por ocupar o lugar da normalidade que o mal esconde o seu horror, o seu escândalo. Novamente podemos nos remeter aos casos de bullying. Quando um estudante agride seu colega sem motivos que justifiquem sua ação. E essa agressão torna-se uma constante, sem que ninguém se manifeste contra a violência que está sendo empregada, o comportamento bullying é banalizado e assume o lugar de normalidade. Esse processo se repete múltiplas vezes e é nesse contexto que a banalidade do mal esconde o escândalo e o horror que o bullying acarreta para todos os envolvidos.

Quando interrogados sobre a autoria das práticas de bullying nos chama a atenção a grande quantidade de respostas superficiais que os estudantes apresentam. Na fase empírica

\begin{tabular}{|l|l|l|l|l|}
\hline Qevista Dialectus & Ano 9 & n. 19 & Agosto-Dezembro 2020 & p. $176-196$ \\
\hline
\end{tabular}


da pesquisa, 147 questionários foram aplicados aos estudantes do Colégio Guarani e serão analisados no quarto capítulo desta tese. Entre as questões abertas, perguntamos aos estudantes que motivos os levam a agredir seus colegas? As respostas nos permitiram relacionar os dados encontrados com a "banalidade do mal", pois corroboraram a tese da ausência de profundidade e da superficialidade dos motivos.

No geral, os estudantes responderam que há três "motivos" que levam às práticas de bullying:

1- Busca pelo poder: "uma forma de mostrar superioridade sobre os demais"; "o fato de eles acharem que são superiores a determinada pessoa e fazer questão de humilhá-la"; "eles querem se sentir melhor do que os outros"; "basicamente, insegurança com relação a si próprios, o que os leva a querer inferiorizar outros para se sentirem melhor"; "o sentimento de querer ser melhor"; "a busca de alguma liderança, status na escola”.

2- Exibição individual: "fazer os outros rir"; "se divertir"; "atenção recebida pela ação"; "aparecer".

3- Causar sofrimento: "achar graça no sofrimento dos outros"; "falta de amor próprio, falta de respeito e consciência que está machucando outra pessoa"; "pode ser a intenção de fazer o outro sofrer, talvez por conta do que aconteça em casa"; "tornar o alvo motivo de piada, gastação entre a galera"; "não terem respeito pelas outras pessoas, não terem valores”.

Ora, buscar uma liderança, desejar ser popular e fazer o outro sofrer sem nenhum motivo precedente nos parece superficial para justificar agressões psicológicas e físicas tão graves e cruéis quanto às relatadas nas entrevistas e publicizadas pela mídia em diversas escolas no Brasil e no mundo. A sensação que temos é que os agressores de bullying, apesar de terem consciência de suas atitudes são incapazes de refletir sobre as consequências mais profundas das mesmas. Trata-se de um mal que não apresenta causas justificáveis, um mal sem motivos, sem raízes e sem explicações contundentes.

Gomes (2004) pesquisou 25 estudantes do ensino médio que afirmaram já ter praticado bullying, tentando entender por que eles agrediram seus colegas. Os resultados, mais uma vez, nos aproximam da expressão "banalidade do mal": 17 estudantes responderam que

\begin{tabular}{|l|l|l|l|l|}
\hline Qevista Dialectus & Ano 9 & n. 19 & Agosto - Dezembro 2020 & p. $176-196$ \\
\hline
\end{tabular}


não sabiam; 2 estudantes alegaram que os colegas mereceram a agressão, mas não explicitam o porquê; 6 estudantes disseram que não gostavam daquelas pessoas.

É interessante analisar as respostas: "não sei o que me levou a fazer isso"; "eles mereceram"; "não gosto de fulano". Qual a raiz desses argumentos? O que de fato levou esses estudantes a agredir repetidamente seus colegas? Por que eles não conseguiram formular uma resposta que justificasse para si e os demais o motivo do bullying? Será que não perceberam a gravidade e a extensão da maldade?

Apesar de Arendt (1999) ter cunhado a expressão "banalidade do mal" após conhecer e acompanhar o caso Eichmann, não acreditamos que ela se referia a uma situação isolada na qual o mal só poderia ser banalizado naquelas circunstâncias específicas. Para Arendt (1999), Eichmann é um paradigma do homem de massa e, por isso mesmo, este tipo de ser humano precisa ser conhecido, pois ele surge nas sociedades contemporâneas, nas quais os seres humanos são supérfluos e superficiais (ANDRADE, 2010, p. 20). O oficial nazista responsável pelo bom funcionamento da burocracia do regime nazista reúne todas as características do homem contemporâneo, prisioneiro da necessidade, "um animal laborans que tem a vida social "gregária", pois perde toda a noção de pertença a um mundo que é o lugar onde, a palavra e a atividade livres dos homens se conjugavam" (SOUKI, 2006, p. 94). As atitudes de Eichmann e a maneira como ele interpretou suas próprias ações nos ajudam a compreender quem são esses sujeitos capazes de banalizar o mal.

Sujeitos destituídos politicamente, transformados em átomos anônimos entre os vários átomos anônimos da massa, homens sem capacidade política, sem consciência moral, sem vontade, sem julgamento, e por essa razão capazes de seguir ou de fazer o mal. Desde que esses homens se tornam seres supérfluos, eles não são mais um fim em si mesmos, e os seus valores como homens se encontram relativizados; eles passam a ser ao mesmo tempo, vítimas e agentes desse mal banal (SOUKI, 2006, p. 95).

Se Eichmann não é um caso atípico e se podemos interpretá-lo como um paradigma, então, poderíamos indagar se nos casos de bullying a banalização do mal também é oriunda dessa destituição do sujeito, pois "a banalidade do mal consiste em um fenômeno humano que transcende a situação contingente do julgamento de Eichmann" (SOUKI, 2006 p. 101). Não estamos afirmando que os agressores de bullying teriam a mesma personalidade de Eichmann, mas podemos pensar até que ponto adolescentes numa escola/sociedade de massas, capaz de industrializar a própria cultura, também pertencem a uma realidade social que vem naturalizando a violência, banalizando os valores, os julgamentos e, até mesmo, a política

\begin{tabular}{|l|l|l|l|l|}
\hline Qevista Dialectus & Ano 9 & n. 19 & Agosto-Dezembro 2020 & p. $176-196$ \\
\hline
\end{tabular}


enquanto instrumento de organização da vida social. O que gostaríamos de ponderar é que o diagnóstico da primeira geração da Escola de Frankfurt ainda se aplica: vivemos em uma sociedade de massas alienada pelas fontes de dominação capitalistas e a escola parece não estar alheia ou imune a esta realidade social. Se a realidade em que vivemos é marcada por sujeitos supérfluos e descartáveis, que perderam a capacidade de pensar e refletir, esses sujeitos podem se tornar vítimas e agentes do processo de banalização do mal, incluindo o ambiente escolar.

Consideramos que, na escola, a banalização do mal não atinge apenas os agressores de práticas de bullying, mas também as vítimas e as testemunhas. A diferença é que os agressores possivelmente agem banalizando o mal com o objetivo de atingir seus pares, enquanto as testemunhas e as vítimas atingidas por essa maldade banalizada contribuem para efetivação desse processo quando não denunciam (no caso das testemunhas) e/ou não conseguem reagir (no caso das vítimas). E por que se omitem? Por que não conseguem reagir? Provavelmente porque acreditam que aquela maldade é natural, é comum, faz parte do cotidiano escolar. Se esse for o caso, o mal assume o lugar da normalidade e isso o faz banalizado, pois ele esconde o lugar do horror e do escândalo.

Arendt (1999) alertou que a banalidade do mal - enquanto fenômeno da condição moderna - alimenta-se de variáveis que precisam ser analisadas, para que os argumentos da maldade inata e das fontes demoníacas possam ser descartados. "Falar da banalidade do mal interdita, de fato, toda dimensão demoníaca, toda maldade essencial, toda maldade inata e, mais amplamente, todo móvel ancorado na depravação, na cobiça e em outras paixões obscuras" (SOUKI, 2006, p. 95). Buscando compreender as variáveis inerentes à banalidade do mal, Charlier (1989) apontou três parâmetros que nos ajudam a entender como a banalidade do mal se organiza.

O primeiro parâmetro é a necessidade, que no caso Eichmann é ilustrada pela existência de um sistema que uniformiza e homogeneíza os sujeitos, busca aniquilar a identidade e enfatiza o lugar de cada um naquela engrenagem. Esse sistema tem a necessidade de transformar todos em iguais uniformizados e contribui para que os sujeitos não se sintam mais responsáveis pelos seus atos, uma vez que perdem a capacidade de reflexão. Se levarmos esse primeiro parâmetro para escola, em específico para compreensão do bullying, podemos considerar algumas interpretações. É evidente que não estamos afirmando que a escola contemporânea funciona sob a égide de um regime nazista. Mas, o sistema educacional atual também é uniformizador, sua estrutura ainda facilita a submissão das diferenças identitárias e enfatiza o lugar que os alunos devem ocupar (CANDAU, 2006). A escola tem a necessidade de

\begin{tabular}{|l|l|l|l|l|}
\hline Qenista Dialectus & Ano 9 & n. 19 & Agosto-Dezembro 2020 & p. $176-196$ \\
\hline
\end{tabular}


tornar todos os estudantes iguais e seguidores passivos de normas. A diferença ainda é pouco trabalhada e isso dificulta uma postura contestatória e reivindicatória por parte dos estudantes. Contribui ainda para comportamentos automatizados e irreflexivos, pois a dimensão criativa nos parece ser, em muitas situações, ignorada.

O segundo parâmetro é a irrealidade, que nos regimes totalitários foi expressa pelos clichês, frases prontas, expressões padronizadas que serviram para retirar os sujeitos do mundo real levando-os a viver em um mundo irreal. Mais uma vez não podemos afirmar que a escola constrói um mundo irreal para os estudantes. Pelo contrário, o esforço da escola é justamente preparar os estudantes para os desafios que a sociedade nos impõe. A questão é que dado o potencial normatizador e uniformizador da escola, muitas vezes, a escola protege os estudantes da realidade, evita debates e discussões polêmicas, esconde os conflitos inerentes à convivência humana, subestima a capacidade de compreensão e ainda trabalha com currículos sedimentados e métodos tradicionais que limitam a criatividade e a reflexão. Provavelmente esses são alguns dos motivos que levaram Candau (2006, p. 02) a defender uma proposta de reinvenção da escola:

Reinventar a escola supõe reconhecer a cada pessoa como sujeito de direito. A cada um, a cada uma de nossos alunos e alunas, a nós mesmos. Em realidades muitas vezes marcadas pela negação do outro, pela homogeneização, pelo silenciamento das diferenças, estamos chamados/as a olhar a cada pessoa em sua mais profunda dignidade, em sua mais profunda singularidade. E, ao mesmo, tempo fortalecer processos de construção conjunta em que igualdade e diferença mutuamente se reclamem. (grifos nossos).

O terceiro parâmetro é o mais importante para nossa reflexão: $o$ vazio do pensamento. Nos regimes totalitários, o vazio de pensamento dos sujeitos resulta na submissão, tornando-os incapazes de reagir e de refletir sobre suas próprias vidas e atitudes. "Esse estado de não pensar ensina as pessoas a se agarrarem solidamente às regras de conduta (quaisquer que sejam elas) de uma sociedade e de uma época dadas. O que elas se habituam é a obediência às regras sem o exame de seus conteúdos" (SOUKI, 2006, p. 103). O vazio do pensamento é decorrente da necessidade de tornar todos iguais e da irrealidade caracterizada por não preparar os sujeitos para encarar os desafios da vida. Na escola, o ato de pensar é muitas vezes desmerecido. Em geral, as atividades pedagógicas não incluem momentos de reflexão, não priorizam o "estar só comigo mesmo", o "dois em um” que só o pensamento provoca. Muitas vezes, apenas nas avaliações ou em raros momentos de leitura individual, o silêncio é promovido como atividade pedagógica, abrindo espaço para a atividade do pensamento, tal

\begin{tabular}{|l|c|c|c|c|}
\hline Qevista Dialectus & Ano 9 & n. 19 & Agosto-Dezembro 2020 & p. $176-196$ \\
\hline
\end{tabular}


como Arendt (1989) o concebe. Infelizmente nossos projetos pedagógicos ainda não reconheceram a importância do pensamento, não compreenderam que o pensar é uma atividade do espírito que vai além do conhecer (ARENDT, 1989, p. 34).

Para Arendt (1989), o pensamento é a reflexão sobre o significado das coisas. Toda atividade do pensamento partirá sempre do senso comum, mas trata-se apenas de um ponto de partida, porque o pensar é o abandono do senso comum, do real (aparência), mesmo que momentaneamente. Quando pensamos, tomamos distância do mundo, nos isolamos, refletimos, resignificamos e retornamos ao mundo (ao senso comum, o senso do mundo compartilhado) para estabelecer nossos julgamentos. O pensamento tem a capacidade de dissolver nossas mais sólidas certezas, é como um vento que desarruma tudo e nos dá a oportunidade de tomar novas decisões ou rever nossas escolhas, por isso o pensar é sempre uma novidade, um recomeço.

Segundo Arendt (1989), só o pensamento com sua natureza invisível seria capaz de tornar presente aquilo que materialmente está ausente. O pensar é inerente à condição humana, por isso Arendt (1989) afirmou que não existe uma ausência de pensamento, mas sim uma incapacidade para o pensar, uma espécie de vazio que nunca pode ser absoluto, mas somente contingencial. "O não-pensar é uma experiência humana artificial, algo forjado pelas contingências" (SOUKI, 2006, p. 121). "Pensar e estar completamente vivo são a mesma coisa, e isto implica que o pensamento tem sempre que começar de novo, é uma atividade que acompanha a vida" (ARENDT, 1989, p. 37).

Mas, se o não-pensar é contingencial, a quais contingências podemos atribuir o "vazio do pensamento"? O não-pensar é uma atividade pervertida, que acontece quando determinadas contingências históricas e políticas esvaziam o senso comum (senso compartilhado ou mundo compartilhado), de onde parte o pensamento, e no lugar do senso comum é imposto de modo autoritário uma ideologia totalitária, uniformizadora, normatizadora, que interdita a espontaneidade humana para o pensamento (ARENDT, 1999).

Primeiramente, há uma supressão do senso comum interditando o contato com a realidade; a seguir, uma impossibilidade de se "parar-para-pensar", engolida por uma ideologia do movimento e, finalmente, a indução ao conformismo. Com a experiência desse percurso, o homem passa a condição de "ser que não pensa", a um autômato, sem memória, sem identidade e sem responsabilidade. Nesse contexto de deterioração humana, dissolvem-se os parâmetros de bem e de mal, de certo e errado, de justo e injusto, o homem não pensa e não julga, só age, indiferentemente, como um instrumento do mal, como nos fala Kant. Nessa situação extrema e perversa o homem é, ao mesmo tempo, vítima e instrumento desse mal (SOUKI, 2006. p. 124-125).

\begin{tabular}{|c|c|c|c|c|}
\hline Qevista Dialectus & Ano 9 & n. 19 & Agosto - Dezembro 2020 & p. $176-196$ \\
\hline
\end{tabular}


É nesse contexto que se instaura a banalidade do mal. Mais uma vez é importante lembrar que o mal nunca é banal e sim banalizado. A principal característica da banalidade do mal é a ausência do pensamento. Essa ausência provoca a privação de responsabilidade, de modo que o praticante do mal se submete a uma lógica externa e não enxerga a sua responsabilidade nos atos que pratica. Age como mera engrenagem. Não se interroga sobre o sentido da sua ação ou dos acontecimentos ao seu redor.

\begin{abstract}
O praticante do mal banal renuncia à capacidade pertencente aos humanos de mudar o curso das ações rotineiras através do exercício da vontade própria. Repete heteronomamente o seu comportamento. Não se reconhece dotado de vontade, capaz de iniciar, fundar e começar. Ele também não exercita a habilidade, peculiar aos homens, de falar e comunicar o que está vendo e sentindo. Vive sem compartilhar o mundo com os outros. Renúncia, desse modo, à faculdade do julgamento. Em suma, recusa-se a viver com os dons provenientes das suas faculdades espirituais: pensar, querer e julgar (AGUIAR, 2010 p. 16).
\end{abstract}

O contexto em que o mal é banalizado é o Estado totalitário, onde o vazio do pensamento é preenchido pela ideologia do conformismo. Se pensarmos no cotidiano escolar guardando as devidas proporções, pois a escola não é um ambiente de exceção, administrado pela ideologia totalitária - podemos indagar até que ponto a violência presente nas práticas de bullying não poderia ser interpretada como uma contingência histórica e política. Histórica, porque acreditamos que o bullying, entre outros motivos, está relacionado à dificuldade que os estudantes encontram em conviver e aceitar as diferenças. Aprendemos com Taylor (2000) que essa dificuldade é oriunda de uma mudança histórica de paradigma, quando o ideal de igualdade tornou-se insuficiente diante da reivindicação social de uma nova ética da autenticidade, "o ser fiel a mim mesmo", que tornou a diferença digna de reconhecimento social e jurídico. Essa transformação histórica resultou também em uma transformação política, inaugurando um dos principais dilemas da modernidade: o debate entre liberais e comunitaristas, defensores, respectivamente, das políticas da igualdade e das políticas da diferença.

Será que a diferença é renegada, apontada, estereotipada, intolerada e discriminada por que estaríamos vivenciando um processo ideológico que inferioriza constantemente os diferentes? Se isso procede, será que podemos pensar que essa ideologia invade cotidianamente o senso comum (o mundo comum compartilhado de onde parte o pensamento), contamina nossa capacidade de pensar e nos leva ao conformismo? Nesse caso, será que esse conformismo nos leva a acreditar que a diferença deve ser tratada com inferioridade? Se esse raciocínio estiver coerente, a banalização do mal acontece no momento em que tratamos a diferença com desprezo

\begin{tabular}{|l|l|l|l|l|}
\hline Qevista Dialectus & Ano 9 & n. 19 & Agosto-Dezembro 2020 & p. $176-196$ \\
\hline
\end{tabular}


porque perdemos a espontaneidade para pensar e porque nossa capacidade de pensar está ausente, contaminada por valores artificiais e meramente normativos, que nos impede de estabelecer um julgamento verdadeiro. "Esse esvaziamento do pensar, operado pela ideologia, produz à indiferença ao mal”. (ARENDT, 1999, p. 56).

Nessa perspectiva, consideramos que, na escola, o bullying poderia ser uma expressão da banalização do mal, se interpretarmos este comportamento como um conjunto de ações maldosas decorrentes da intolerância que permeia as relações sociais dentro do ambiente escolar. Um tipo específico de violência escolar onde o processo de banalização do mal corresponde às práticas discriminatórias diante da diferença, quando esta incomoda simplesmente por existir.

Ao relacionar o mal ao vazio do pensamento, Arendt (1999) aponta para uma possível compreensão da violência nas sociedades contemporâneas. Por isso, a partir de seus estudos podemos arriscar afirmar que nas sociedades atuais, o mal se realiza na banalidade, ou seja, na recorrência das radicais práticas de violência, na maioria das vezes contra aqueles que são diferentes: os apátridas, os imigrantes, as mulheres, os desempregados, os indígenas, os negros, os idosos, os homossexuais, etc.

Mas, se o problema está no vazio do pensamento, no fato do pensar ser esvaziado por ideologias artificiais, seria o pensamento uma condição suficiente para a garantia de não se fazer o mal? Em outras palavras, será que o pensamento é capaz de impedir a banalidade do mal? Arendt (1999) responde esses questionamentos defendendo que o pensamento é uma condição necessária para impedir o mal, mas não é o suficiente. "Isso porque o pensamento não cria valores, ele não pode descobrir sozinho o que é o "bem", e não confirma as regras aceitas de conduta; mas, antes, dissolve-as" (SOUKI, 2006, p. 125). Somente em sua relação com o julgar (segunda faculdade do espírito) é que o pensamento pode efetivar sua plena realização com autonomia e se afastar de todos os tipos de conformismos, isso porque o julgar é uma faculdade própria do espírito. Mas, se o pensamento for esvaziado e estruturado a partir de um senso comum artificialmente contaminado, o julgar tende a reproduzir o conteúdo do senso comum, pois "o julgamento é o que reconcilia pensamento e senso comum” (ARENDT, 1991, p. 79).

A diferença desafia a escola e, em geral, é vista e tratada como negativa. O senso comum que se produz e reproduz no cotidiano escolar nos parece estar contaminado pela ideologia da intolerância à diferença. Esse cenário tende a esvaziar o pensamento de estudantes e professores, contribuindo para julgamentos preconceituosos, intolerantes e discriminatórios.

\begin{tabular}{|l|l|l|l|l|}
\hline Qenista Dialectus & Ano 9 & n. 19 & Agosto-Dezembro 2020 & p. $176-196$ \\
\hline
\end{tabular}


Talvez, por isso, quando interrogamos os estudantes sobre os motivos que os levam a praticar o bullying as respostas nos parecem vazias, injustificáveis, sem conteúdo. Boa parte das pesquisas analisadas na revisão de literatura enfatiza a falta de motivação significativa como uma característica do bullying, e essa visão é também compartilhada por Olweus (1978) e tem sido um dos temas menos investigado no campo. Assim, entendemos que Arendt (1989; 1999), com seus estudos sobre a banalidade do mal, pode nos ajudar a compreender melhor este aspecto do bullying.

A banalidade do mal tem a capacidade de transformar o mal em algo comum e esconder sua monstruosidade. É isso que acreditamos acontecer no comportamento bullying. $\mathrm{O}$ estudante que agride seu par, quando interrogado sobre sua atitude, não consegue compreender a gravidade de sua ação, entende seu comportamento como algo normal, geralmente culpabiliza a vítima, colocando nela algum defeito que supostamente justificaria a ação. Muitas vezes, admite não saber o que o levou a praticar determinada violência. Como isso é possível? O que faz com que crianças e adolescentes violentem repetidamente seus pares acreditando que suas atitudes são normais? Como as escolas e as famílias podem interpretar essas maldades como normais, como fatos corriqueiros, coisas de criança? Como o mal pode se tornar banal e esconder seu escândalo?

O mal se torna banal porque os seus agentes são superficiais e suas vítimas são consideradas supérfluas. “Quanto mais superficial alguém for, mais provável será que ele ceda ao mal. Uma indicação de tal superficialidade é o uso de clichês, e Eichmann era um exemplo perfeito" (ASSY, 2001, p. 145). Quanto à superfluidade da vida humana, Arendt (1989, p. 510) afirma que este tem sido um fenômeno decorrente do sentido extremamente utilitário das sociedades de massa (ANDRADE, 2010, p. 23).

Tanto para Kant (1974) quanto para Arendt (1999), o mal se realiza quando o ser humano deixa de ser um fim em si mesmo, perdendo assim toda a sua dignidade. Nas sociedades de massa, além de perder sua dignidade, o ser humano é transformado em um instrumento. "Sua existência já não se justifica por si mesma, mas se torna condicionada a um valor utilitário, a um valor relativo às necessidades definidas pelas contingências históricas e políticas”. (SOUKI, 2006, p. 129). No momento em que a vida humana é relativizada a esse ponto, perde seu significado, deixando assim de ser importante, necessária, essencial e transformando-se em banal.

Mais uma vez podemos nos remeter às práticas de bullying. Se levarmos em consideração que os agressores de bullying são estudantes superficiais, que apresentam

\begin{tabular}{|l|l|l|l|l|} 
Govista Dialectus & Ano 9 & n. 19 & Agosto-Dezembro 2020 & p. $176-196$ \\
\hline
\end{tabular}


dificuldade em reconhecer e aceitar as diferenças de suas vítimas, muito provavelmente porque não conseguem pensar de modo reflexivo. Talvez, essa dificuldade seja semelhante à de Eichmann, que teve seus pensamentos esvaziados, e no lugar destes, foram colocadas frases prontas, clichês e preconceitos (juízos enraizados e não refletidos). Eichmann não tinha ódio dos judeus, mas os considerava supérfluos, pessoas sem importância. Será que não é exatamente isso que os agressores de bullying pensam sobre suas vítimas? Será que não é isso que os faz banalizar a maldade? Será que quando um estudante obriga seu colega a tomar sua própria urina (um caso narrado nas entrevistas) ele considera seu colega como uma pessoa digna de respeito? Ou ele pratica essa maldade por que enxerga seu colega como alguém superficial, sem valor?

A banalidade do mal está além do mal radical no sentido kantiano, não podemos entendê-la apenas como um desvio moral. Quando o mal é banalizado, a vítima dessa maldade é vista como descartável e invisível, e todo seu sofrimento assume o lugar da normalidade. Quando escolas e famílias tratam o bullying como algo normal, a nosso juízo, estão contribuindo para a banalização da maldade, estão sendo coniventes com a transformação de estudantes em sujeitos superficiais e estão cooperando para que o horror seja escondido.

\section{Concluindo o inconclusivo}

Nesse texto buscamos problematizar a motivação para as práticas de violência escolar, em específico os casos de bullying. Consideramos pensar o bullying como uma expressão da banalização da maldade, e diante das narrativas dos estudantes coletadas com as entrevistas, nos vimos diante de casos de extensa humilhação e de situações conflituosas que nos mostraram que as relações sociais entre pares são estruturadas na banalização da maldade, no sentido de xingar e ofender o outro de modo comum e corriqueiro, como se aquele tipo de tratamento ofensivo e desrespeitoso fizesse parte do cotidiano dos jovens, ao ponto de alguns deles não identificarem o desrespeito. A questão é se essa normalidade aparente também é sentida pela vítima, ou seja, por aqueles estudantes que são alvos desse tipo de tratamento. Assim, podemos problematizar se esses xingamentos, humilhações e ofensas que ocupam o lugar da normalidade não se enquadram em um processo de banalização da maldade e naturalização da violência.

Atitudes com rir e debochar da situação de sofrimento do outro foram destacadas e sempre pontuadas como algo comum, normal que acontece todos os dias. E, talvez ainda mais grave, como algo que não pode ser impedido e que a escola não conseguiria evitar. Reconhecer

\begin{tabular}{|l|l|l|l|l|}
\hline Qenista Dialectus & Ano 9 & n. 19 & Agosto - Dezembro 2020 & p. $176-196$ \\
\hline
\end{tabular}


que a violência escolar acontece, e não é uma mera brincadeira é apenas o primeiro passo. Acreditamos e defendemos que além desse reconhecimento um caminho possível para compreender e enfrentar essa banalização da maldade, que caracteriza as práticas de violência seria investir numa proposta pedagógica de educação para o pensamento e para diferença. Mas, o que seria isso? Os estudantes reconhecem que o bullying é prejudicial, mas quando são interrogados sobre porque continuam agredindo seus colegas não conseguem formular uma resposta convincente. Por que não conseguem? Provavelmente porque não pensam em suas atitudes, não refletem e não são incentivamos a refletir sobre seus valores, suas identidades e que tipo de ser humano gostariam de se tornar. Educar para o pensamento e para a reflexão significaria cultivar em nós e em nossas relações educativas atitudes que possibilitem o diálogo interno como uma atividade inerente à vida humana.

\footnotetext{
Quando estou pensando não me encontro onde realmente estou; estou cercada não por objetos sensíveis, mas por imagens invisíveis para os outros. É como se eu tivesse me retirado para uma terra dos invisíveis, da qual nada poderia saber, não fosse esta faculdade que tenho de lembrar e imaginar. O pensamento anula distâncias temporais e espaciais. Posso antecipar o futuro, pensá-lo como se já fosse presente, e lembrar do passado como se ele não tivesse desaparecido (ARENDT, 1995, p. 67).
}

O pensamento interrompe todas as nossas atividades, deixa-nos inseguros quando percebemos que duvidamos de coisas que antes nos davam uma segurança irrefletida. Educar, na perspectiva do pensamento arendtiano, é provocar essa descontinuidade, uma ruptura com o mundo cotidiano para reconciliar-se com ele num novo significado (ANDRADE, 2010, p.127). Essa ruptura é fundamental para que a banalização da maldade que permeia as relações intersubjetivas dos estudantes não se consolide e não se transforme em práticas de bullying.

Segundo Andrade (2010), educar para o pensamento é um também caminho de educar para diferença, pois quando mostramos aos estudantes que somos constituídos a partir de múltiplas diferenças e que viver dignamente é ter essas diferenças reconhecidas e respeitadas, estamos contribuindo para que eles possam pensar e refletir sobre a importância da diversidade no mundo em que vivemos. Educar para diferença é fundamental se queremos construir uma sociedade justa e plural. Educar para diferença significa não tolerar a intolerância, não aceitar os diversos tipos de preconceitos e discriminações, em última instância, educar para a diferença é uma forma de combater as práticas de bullying que nascem da incapacidade de aceitar e conviver com o diferente.

\begin{tabular}{|l|l|l|l|l|}
\hline Qevista Dialectus & Ano 9 & n. 19 & Agosto-Dezembro 2020 & p. $176-196$ \\
\hline
\end{tabular}




\section{Referências Bibliográficas}

ANDRADE, M. Tolerar é Pouco? Pluralismo, mínimos éticos e prática pedagógica. Petrópolis, RJ: DP ET Alii: De Petrus; Rio de Janeiro: Novamérica, 2009.

A banalidade do mal e as possibilidades da educação moral: contribuições arendtianas. Revista Brasileira de Educação, v. 15, 2010.

ARENDT, Hannah. Homens em tempos sombrios. Trad. Denise Bottmann. São Paulo: Companhia das Letras, 1987.

As origens do totalitarismo: antissemitismo, imperialismo, totalitarismo. Trad. Roberto Raposo. São Paulo: Companhia das Letras, 1989.

Eichmann em Jerusalém: um relato sobre a banalidade do mal. Trad. José Rubens Siqueira. São Paulo: Companhia das Letras, 1999.

ASSY, Bethânia. Eichmann, banalidade do mal e pensamento em Hannah Arendt. In: MORAES, Eduardo J.; BIGNOTTO, Newton (Orgs.). Hannah Arendt: diálogos, reflexões, memórias. Belo Horizonte: Editora UFMG, 2001

BERNSTEIN, Richard. ¿Cambió Hannah Arendt de opinión?: del mal radical a la banalidad del mal. In: BIRULÉS, Fina. Hannah Arendt: el orgullo de pensar. Trad. Xavier Calvo. Barcelona: Gedisa, 2008.

CANDAU, V. M. (Org.). Cultura (s) e educação: entre o crítico e o pós-crítico. Rio de Janeiro: DP\&A, 2005.

CANDAU, Vera Maria; SACAVINO, Suzana (Coords). Educação em Direitos Humanos e bullying: Oficinas para o enfrentamento e prevenção. Rio de Janeiro: Novamerica, 2012.

Direitos humanos, educação e interculturalidade: as tensões entre igualdade e diferença. Revista brasileira de Educação, v.18, 2006.

JARDIM, Eduardo. Hannah Arendt: pensadora da crise e de um novo início. Rio de Janeiro: Civilização Brasileira, 2011.

KANT, I. Fundamentação da metafísica dos costumes. São Paulo. Abril Cultural, 1974.

KOHN, Jerome. O mal e a pluralidade: o caminho de Hannah Arendt em direção à Vida do espírito. In: AGUIAR, Odílio Alves et al. (Org.). Origens do totalitarismo: 50 anos depois. Rio de Janeiro: Relume Dumará, 2001. p. 9-36.

OLWEUS, D. Aggression in the schools: Bullies and whipping boys. Washington, D.C.: Hemisphere (Wiley), 1978.

\begin{tabular}{|l|l|l|l|l|}
\hline Q Povista Dialectus & Ano 9 & n. 19 & Agosto-Dezembro 2020 & p. $176-196$ \\
\hline
\end{tabular}


SOUKI, Nádia. Hannah Arendt e a banalidade do mal. Belo Horizonte: Editora UFMG, 2006.

TAYLOR, C. Argumentos filosóficos. São Paulo: Edições Loyola, 2006.

As fontes do Self: A construção da identidade moderna. São Paulo: Edições Loyola, 2001.

\begin{tabular}{|l|l|l|l|l|}
\hline Qevista Dialectus & Ano 9 & n. 19 & Agosto - Dezembro 2020 & p. $176-196$ \\
\hline
\end{tabular}

